\title{
Terceirização nas universidades públicas a partir da percepção das classes representativas: $O$ caso da Universidade Federal de Rondonópolis
}

\author{
Outsourcing en universidades públicas desde la percepción de clases de \\ representantes: El caso de la Universidad Federal de Rondonópolis \\ Outsourcing in public universities from the perception of \\ representative classes: The case of the Federal University of Rondonópolis
}

\author{
Bel. Suellen Moura Leite ${ }^{1}$ \\ Dr. Edir Vilmar Henig ${ }^{2}$
}

\begin{abstract}
Resumo
No Brasil, a terceirização na Administração Pública avançou no governo de Fernando Henrique Cardoso com a Reforma do Estado alterando de vez o funcionalismo público. Este estudo buscou compreender como as Classes Representativas da Universidade Federal de Rondonópolis percebem o processo de terceirização nas Universidades Públicas. Em relação aos aspectos metodológicos, utilizou-se o método qualitativo e a pesquisa documental. Foram entrevistados três representantes de cada classe e um fiscal de contrato responsável pelos contratos de fornecimento de mão de obra da instituição. Os resultados apontaram no período de 2015 a 2018 o estabelecimento de dezesseis contratos de terceirização e o número de cento e oito terceirizados nas atividadesmeio da instituição. Em relação às classes representativas constatou-se o aumento das contratações dos professores substitutos nos cursos de graduação e a insuficiência de vagas em concursos públicos para docentes e técnico administrativos. A pesquisa revelou ainda, que os trabalhadores terceirizados, sobretudos os da limpeza tem a força de trabalho mais explorada e estão vulneráveis em relação à garantia dos seus direitos trabalhistas.
\end{abstract}

Palavras-chave: Terceirização. Classes representativas. Universidades Públicas.

\section{Resumen}

En Brasil, la subcontratación en la Administración Pública avanzó bajo el gobierno de Fernando Henrique Cardoso con la Reforma del Estado, alterando el servicio civil de una vez por todas. Este estudio tuvo como objetivo comprender cómo las clases representativas de la Universidad Federal de Rondonópolis perciben el proceso de subcontratación en las universidades públicas. En cuanto a los aspectos metodológicos, se utilizó el método cualitativo y la investigación documental. Se entrevistó a tres representantes de cada clase y un inspector de contratos responsable de los contratos de suministro de mano de obra de la institución. Los resultados señalaron en el período 2015-2018 el establecimiento de dieciséis contratos de subcontratación y el número de ciento ocho subcontratados en las actividades intermedias de la institución. Con respecto a las clases representativas, hubo un aumento en la contratación de maestros sustitutos en cursos de pregrado y la falta de vacantes en concursos públicos para maestros y técnicos administrativos. La encuesta también reveló que los trabajadores subcontratados, especialmente los de limpieza, tienen la fuerza laboral más explotada y son vulnerables a garantizar sus derechos laborales.

Palabras clave: Outsourcing. Clases representativas. Universidades públicas

\footnotetext{
1 Bacharel em Administração, Universidade Federal de Mato Grosso, Rondonópolis, Mato Grosso, Brasil. mourahand100_@hotmail.com.

${ }^{2}$ Doutor em Território, Risco e Políticas Públicas, Universidade do Estado de Mato Grosso, Juara, Mato Grosso, Brasil. edirhenig@ hotmail.com.
} 


\begin{abstract}
In Brazil, outsourcing in the Public Administration advanced in the government of Fernando Henrique Cardoso with the Reform of the State altering the civil service of time. This study sought to understand how the Representative Classes of the Federal University of Rondonópolis perceive the process of outsourcing in Public Universities. Regarding the methodological aspects, the qualitative method and the documentary research were used. Three representatives of each class were interviewed and a contract prosecutor responsible for the institution's labor supply contracts. The results indicate that in the period from 2015 to 2018 the establishment of sixteen outsourcing contracts and the number of outsourced ones in the institution's middle activities. In relation to the representative classes, there was an increase in the hiring of substitute professors in undergraduate courses and the lack of vacancies in public competitions for teachers and administrative technicians. The survey also revealed that outsourced workers, those who are overworked, have the most exploited labor force and are vulnerable to the guarantee of their labor rights.
\end{abstract}

Keywords: Outsourcing. Representative Classes. Public. Universities.

\title{
1. Introdução
}

As transformações ocorridas no cenário econômico nos últimos anos e as dificuldades orçamentárias enfrentadas pelas Universidades Públicas, a terceirização aparece como uma alternativa de modelo de subcontratação de trabalho. Esse processo é resultado da expansão mundial do neoliberalismo a partir dos anos 1980 e 1990, no Brasil tem início no governo do ex-presidente Fernando Henrique Cardoso. Na década de 1990, o governo iniciou a Reforma do Estado pautada na redução de verbas e gastos com abertura de concursos públicos com o objetivo de diminuir o tamanho da "máquina estatal". As privatizações nos órgãos públicos se tornaram frequentes e alterações nas relações contratuais de trabalho foram realizadas para se adequar ao momento de grandes transformações na economia brasileira naquela época.

Alguns estudos apontam que a terceirização na Administração Pública não resultou em economicidade e eficiência na execução dos serviços públicos. Ao contrário do que se afirmar sobre as vantagens da terceirização, o que mais pode ser visto é a precarização do trabalho como resultado da implantação desse modelo produtivo nos órgãos públicos. A rotatividade das empresas terceirizadas, o descumprimento das obrigações trabalhistas dos funcionários e as más condições de trabalho impostas aos trabalhadores terceirizados são as principais consequências desse modelo de subcontratação.

No intuito de levantar discussões inerentes ao fenômeno da terceirização em expansão nas Universidades Públicas que respondem expressivamente pelas contratações de mão de obra terceirizada, sobretudo presente nas atividades-meio dessas instituições, contrapondo a redução de concursos públicos para estas universidades, questiona-se: qual é a percepção das Classes Representativas no processo de terceirização das Universidades Públicas?

Este estudo foi realizado na atual Universidade Federal de Rondonópolis, a instituição recém-criada pela Lei 13.637/18 que autorizou o desmembramento do Campus da 
Universidade Federal de Mato Grosso. A presente Lei estabeleceu as diretrizes para a composição do quadro de pessoal da UFR, haja vista os cargos vagos na instituição. Em relação a estes cargos Silva, Menezes e Vasconcelos (2018) afirmam no estudo realizado na instituição, que tais cargos vagos não serão preenchidos via concurso público, abrindo assim precedência para o processo de terceirização.

O estudo buscou compreender como as Classes Representativas da Universidade Federal de Rondonópolis percebem o processo de terceirização nas Universidades Públicas. Durante a realização da pesquisa foram estabelecidos os seguintes objetivos: (a) identificar as classes representativas e as empresas terceirizadas da UFR; (b) apresentar os dados da terceirização na UFR de 2015 a 2018, (c) contextualizar a percepção das classes representativas com os dados coletados do processo da terceirização da UFR. Em relação aos aspectos metodológicos adotou-se o método qualitativo e a pesquisa documental para a coleta dos dados institucionais da universidade estudada.

As transformações sociais ocorridas no mundo do trabalho, a exemplo da Reforma das Leis Trabalhistas, a promulgação da Lei 13.4.29/17 da terceirização irrestrita e os mais recentes decretos publicados em 2018 implicaram na redução do funcionalismo público. A partir desse contexto social de ordem econômica, sobretudo a aplicação de políticas neoliberais para a Administração Pública moldando a gestão inclusive das Universidades, questiona-se: Qual é a percepção das Classes Representativas em relação ao processo de terceirização nas Universidades Públicas?

Os objetos de estudo é a terceirização na UFR a partir da percepção das classes representativas (sindicato, as associações de professores e estudantes), e um fiscal de contrato responsável por alguns contratos terceirizados de fornecimento de mão de obra da instituição. O critério de escolha adotado considerou o nível de representatividade político-social dessas entidades que atuam na Universidade, e quanto ao fiscal de contrato, a escolha foi de caráter técnico. A experiência na fiscalização e acompanhamento dos contratos de fornecimento de mão de obra foram os princípios que nortearam a escolha para este fiscal de contrato.

Em relação aos procedimentos metodológicos na coleta de dados, adotou-se a entrevista semiestruturada para cada um dos representantes das classes e ao fiscal de contrato. O roteiro de entrevista foi composto por perguntas abertas referente ao problema da pesquisa, e ao procedimento da fiscalização e acompanhamento do contrato terceirizado na Administração Pública.

\section{A terceirização na administração pública}


A terceirização surge após as mudanças ocorridas nos meios de produção da indústria, sobretudo a partir do modelo japonês toyotismo que introduziu a chamada produção flexível. Behring (2008) relaciona a automatização da produção e a descentralização produtiva como as principais características da produção flexível no modelo japonês. Tais características foram responsáveis pelas alterações nas relações de trabalho no setor público e privado, além disso proporcionou o surgimento de mais empresas na modalidade de subcontratação.

Druck (1995) ressalta a intensificação e a generalização das práticas de gestão do trabalho presente no modelo de produção japonês que deu origem a terceirização. A autora salienta ainda que a rede de subcontratação pelo processo de descentralização da produção resultou no crescimento acentuado de micro e pequenas empresas que mantém em sua maioria os contratos precários de trabalho.

No Brasil, a introdução da terceirização no setor público conforme Druck et al. (2018), ocorre no período militar em 1967, após uma reforma administrativa no Estado com o objetivo de reduzir o crescimento da "máquina estatal". Tal ação foi regulamentada a partir da publicação do Decreto 200/1967 permitindo a descentralização na Administração Pública e a concessão da execução indireta de serviços por uma empresa privada. Na ocasião, um marco histórico na relação pública e privada para a época resultando no avanço expressivo de empresas de prestadoras de serviços e na redução de investimentos pelo Estado nos órgãos públicos.

Na década de 1990, o governo de Fernando Henrique Cardoso (1994 - 2002) realizou a Reforma Administrativa no Estado alterando o funcionalismo público brasileiro. Behring (2008) relata que na ocasião, o governo importou conceitos gerenciais de países como a França e Inglaterra implantando assim, a lógica da iniciativa privada nos órgãos públicos. A autora relata ainda, a incorporação de termos de gestão como metas, gerentes, gestores públicos, resultados e qualidade total na Administração Pública. A implantação do regime gerencialista nos órgãos públicos pelo governo alterou consideravelmente a gestão e a estrutura organizacional destas instituições.

As investidas neoliberais presentes no Governo de Fernando Henrique Cardoso prosseguiram na promulgação de leis e decretos para a Administração Pública, como o Decreto 2271/97 sobre a descentralização das atividades do Estado. Tal decreto estabeleceu as diretrizes para a terceirização no setor público com a autorização somente nas atividadesmeio. As atividades passíveis de terceirização eram: conservação, limpeza, segurança, vigilância, transportes, informática, copeiragem, reprografia, telecomunicações e manutenção 
de prédios, equipamentos e instalações. Embora, esse decreto favorecia a parceria públicoprivada havia uma limitação imposta pelo governo de controlar as contratações indiretas na Administração Pública.

O governo sancionou em seguida a Lei 9.637/1998 que tratava da subcontratação pelo Poder executivo de Organizações Sociais (OSS). As OSS eram compostas por pessoas jurídicas de direito privado as quais podiam atuar livremente nas áreas de ensino, pesquisa científica, desenvolvimento tecnológico, proteção, conservação do meio ambiente, cultura e saúde. Conforme Druck et.al (2018), a participação das OSS no setor público resultou no aumento exacerbado dessas organizações nas atividades-fim, principalmente nas áreas de educação e saúde, configurando em terceirização ilícita.

As discussões sobre a terceirização no país novamente vêm à tona a partir do PL 4.330/04 sobre a regulamentação da terceirização no país, tal iniciativa resultou posteriormente na Lei 13.429/17. A nova Lei da terceirização é decorrente da. Lei 6.019 de 1974 que dispõe das regras de contrato temporário nas empresas urbanas. As alterações mais significativas dessa nova lei é que agora a prestadora de serviços pode executar quaisquer atividades da contratante, inclusive sua atividade principal, e mais, a própria prestadora de serviços pode terceirizar esses serviços para uma outra empresa, prática que se configura como quarteirização.

A Lei 13.429/17 trouxe mudanças significativas nas relações de trabalho tanto para a iniciativa privada como para a Administração Pública. No âmbito do setor público, há uma preocupação por parte das entidades representativas em relação ao avanço do processo de terceirização na execução das atividades-fim, e o aumento de profissionais contratados exercendo as mesmas funções que um servidor público de carreira. No ano de 2018, o então presidente Michel Temer sancionou o Decreto 9.262/2018 que tratava da vedação de abertura de novos concursos públicos. Posteriormente foram publicados o Decreto 9507/18 e a Portaria 443/18, os quais facilitaram a expansão de atividades que agora podem ser terceirizadas na Administração Pública.

O Decreto 9507/18 facilitou a expansão da terceirização na medida que há uma proibição somente em serviços que envolvam a tomada de decisão ou de posicionamento institucional, ou que sejam considerados estratégicos para o órgão ou a entidade, de regulação, outorga de serviços públicos, aplicação de sanção, de categorias funcionais abrangidas no plano de cargos do órgão. Sendo assim, todas as outras atividades poderão ser terceirizadas, inclusive atividades exercidas nos setores administrativos das instituições públicas. 
A Portaria 443/18 cita as atividades que serão executadas preferencialmente de execução indireta. Tais atividades são realizadas preferencialmente pelos setores administrativos das universidades como: as atividades auxiliares técnicas de biblioteconomia, atividades auxiliares técnicas de laboratório, comunicação social, secretariado, serviços de escritório e de apoio à gestão documental, serviços de tecnologia da informação.

Entretanto, percebe-se que ainda há uma lacuna nesses decretos a medida que cargos que não foram extintos e estão presentes no Plano de Carreira dos servidores públicos, principalmente os cargos presentes nas universidades. Mas, que já estão passíveis de serem terceirizados conforme determina esta portaria publicada pelo ex-presidente Michel Temer.

Recentemente foi publicado o Decreto 9725/19 que trata da extinção de cargos em comissão, funções gratificadas e funções de confiança no âmbito do Poder Executivo Federal. Esse Decreto atingirá principalmente as Instituições de Ensino Superior, principalmente as novas universidades federais criadas no de 2018 a partir do desmembramento de outras IFES, como a UFR, por exemplo. O Decreto determina a extinção de quatrocentas e noventa e oito funções comissionadas técnicas, cento e dezenove cargos de direção, mil oitocentas e setenta funções comissionadas de coordenação de curso além de outras funções gratificadas que serão extintas até 31 de julho de 2019.

A partir do Decreto 9725/19 diversos cargos serão extintos ou dispensáveis do exercício de funções gratificadas, dessa forma vários servidores públicos, sobretudo os docentes e técnico-administrativos das Universidades Públicas em exercício nas funções de gestão, direção coordenação de curso e de departamentos não serão mais gratificados. Tal medida prejudicará a qualidade de ensino nas universidades federais, pois aumentará a jornada de trabalho dos professores sem o acréscimo da gratificação, fato que contribui ainda mais para a precarização do trabalho docente nas Universidades Públicas.

\subsection{Implicações sociais da terceirização da administração pública}

Segundo Pochmann (2006), o conjunto das empresas que atuam no Brasil e a consolidação de um novo modelo econômico nos anos 90 trouxe implicações significativas. Para o autor, a conduta empresarial voltada para implantação de novos programas de gestão da produção, de reorganização do trabalho e de inovação tecnológica revelaram novidades adicionais para o emprego e para as relações de trabalho. A principal mudança na realidade das empresas foi adoção da prática de terceirização, tal atitude proporcionou às empresas a possibilidade de transferir suas atividades para serem executadas por outras empresas. 
Antunes (2015, p.09) cita as mudanças advindas da terceirização:

\begin{abstract}
A terceirização vem se constituindo no principal mecanismo, em praticamente todas as partes do mundo, para expandir as formas de acumulação flexível que se desenvolvem através da desconcentração produtiva, das redes de subcontratação(empresas terceirizadas), do trabalho em equipe, da flexibilidade salarial, das "células de produção" dos "times de trabalho", dos grupos "semiautônomos", além de exercitar, ao menos no plano discursivo, o "envolvimento participativo" do(a)s trabalhador(a)s. O "trabalho polivalente", "multifuncional", "qualificado", combinado com uma estrutura mais horizontalizada e integrada entre diversas empresas, inclusive nas empresas terceirizadas, tem como finalidade reduzir o tempo e aumentar a intensidade e exploração de trabalho.
\end{abstract}

A rede de subcontratação, nas palavras de Druck (1995) também chamada de terceirização, surge no plano econômico não só na condição de redução de custos, mas também como estratégia política, à medida que institui um amplo segmento de trabalhadores de segunda categoria, que se distanciam dos de primeira categoria, implicando na perda de identidade de classe. Desta forma, a organização e representatividade coletiva deixa de ser uma prioridade a nesse modelo de subcontratação favorecendo mais facilmente a exploração do trabalhador e a perda de seus direitos.

No entender de Marcelino (2006), o fim da contratação direta da força de trabalho tem implicações direitas na redução dos custos com encargos trabalhistas e no valor da remuneração do trabalho paga em forma de salários. Nesse sentido, a terceirização é uma modalidade contratual que na prática beneficia as empresas, principalmente no momento da contratação e da demissão do funcionário, quando essas decisões deixam de ser onerosas para se tornarem lucrativas sob a exploração da força de trabalho do funcionário terceirizado.

A terceirização não tem a atenção voltada para a qualidade das relações de trabalho entre contratantes e contratados. Para Russo e Leitão (2006) na prática, o que mais pode ser visto é um interesse subtendido de ambas as partes para obtenção de uma vantagem dessa relação contratual. A partir do momento que não se prioriza as condições do trabalho exercido por trabalhadores terceirizados que possuem remuneração bem inferior à média salarial de um trabalhador que exerce o mesmo cargo numa empresa privada convencional, tais práticas evidenciam a promoção de concentração de capital e renda, além da ampliação da desigualdade social.

Druck et al. (2018) associam a reestruturação do aparelho estatal ocorrido em 1995 pelo Governo quando redefiniu a carreira e os cargos públicos à ampliação e a legalização da terceirização nos espaços públicos. As autoras ressaltam ainda a consolidação de um Estado neoliberal que utiliza da terceirização como instrumento para finalizar o segmento dos trabalhadores no funcionalismo público. As consequências desse processo podem ser notadas 
nas más condições de trabalho, no desrespeito dos direitos trabalhistas e principalmente o aumento de acidentes no trabalho, tais situações são enfrentadas diariamente pelos trabalhadores terceirizados.

Silva, Menezes e Vasconcelos (2018), afirmam que o avanço da terceirização precariza a situação do trabalhador, além de promover a eliminação de postos de trabalho. Por outro lado, a Administração Pública não tem meios legais necessários para enquadrar as empresas terceirizadas fraudulentas que possam descumprir alguma das cláusulas do contrato firmado entre as partes. Nesse sentido, a terceirização pode resultar em riscos e aumento de custos para a Administração Pública se for apurado irregularidades no contrato e na obrigação de quitação dos direitos trabalhistas dos trabalhadores terceirizados.

\section{A precarização do trabalho nas Universidades públicas}

As transformações sociais advindas do processo de reestruturação das forças produtivas no trabalho influenciaram não só as relações de trabalho na iniciativa privada como também as instituições públicas. Ao tomarmos como exemplo a Universidade Pública Federal, Aquino et al (2014) salienta que a instituição não ficou imune às essas transformações e os efeitos da política gerencialista podendo ser vista na intensificação do trabalho docente, caracterizada pela prática produtivista.

A Reforma Universitária configura-se na implementação dos processos de privatização com ações produtivistas, aprofundamento da precarização das relações de trabalho, promoção de gratificações ao invés de política salarial, extinção da carreira e da isonomia, diversificação das fontes de financiamento, diferenciação das instituições, expansão das universidades, prioridade do ensino à distância, autonomia financeira das instituições públicas através da captação de recursos e a regulamentação da relação entre universidades e fundações privadas. (GRANZOTTO, 2011, p. 180)

A intensificação do trabalho docente pode ser vista nas normas institucionais de cada universidade, no âmbito da Universidade Federal de Mato Grosso vigora a Resolução 158 sobre as normas para distribuição de encargos didáticos, segundo o regime de trabalho dos docentes. A referida resolução retrata todas as atividades acadêmicas a serem desenvolvidas pelo docente na instituição. A partir desta normativa, constata-se a exigência de muitas atividades no trabalho docente, além do cumprimento de uma carga horária excessiva.

A precarização do trabalho nas Universidades Públicas pode ser notada principalmente nas más condições de trabalho que os servidores públicos efetivos e contratados são submetidos por essa política produtivista de cunho neoliberal. 
Anderson (1995, p. 9) estabelece que o neoliberalismo foi uma reação teórica ao estado de bem estar e das intervenções estatais nas regulações sociais e econômica. Tem por data inaugural o fim da Segunda Guerra, mas acentua-se na década de 1980 espalhando-se pelo globo com incentivo do governo britânico de Thatcher e americano de Reagan. Tendo como objetivo é desaparelhar o Estado, dando máxima liberdade econômica ao mercado, sendo de sua responsabilidade apenas as funções estruturantes que não tenham possibilidade de lucro para o mercado.

Na visão de Aquino et al. (2014), as ideias neoliberais têm por objetivo desestabilizar o sentido social do Estado tornando o setor público cada vez mais mercantilizado. A estratégia mais eficaz na implantação da lógica neoliberal nas Universidades Públicas tem sido a terceirização. Os Estados ao descentralizar os serviços públicos facilitaram a entrada das empresas, estas que consequentemente enxergaram oportunidades de expansão de suas atividades no setor público.

Outra questão a ser analisada é que a terceirização em alguns setores, poderá tornarse o carro chefe para a total privatização das universidades públicas. A terceirização é um recurso utilizado nas universidades para suprir a falta de funcionários, a qual se apresenta atualmente em todas as áreas, sendo que essas contratações são viabilizadas através das fundações ditas "de apoio" e contratos com empresas externas (GRANZOTTO, 2011, p.181).

Kitagawa e Silva (2016) são enfáticos ao afirmarem que os impactos da terceirização trouxeram consequências desastrosas para os trabalhadores. Esses trabalhadores recebem menos, trabalham mais, convivem diariamente com a insegurança e a falta de representação sindical. Tais condições contribuem para a criação de um trabalhador mais vulnerável e sem identidade de classe. Os trabalhadores terceirizados são os mais afetados diretamente com essa modalidade de subcontratação e dessa forma questiona-se a qualidade desta relação de trabalho.

Os estudos realizados pelo Dieese (2017) no ano de 2014, revelam que a terceirização responde por uma elevada taxa de rotatividade do mercado de trabalho brasileiro. Constatouse ainda que a taxa de rotatividade descontada nas atividades tipicamente terceirizadas se manteve alta praticamente em todos os anos analisados pelo estudo. Ao tomarmos como base os dados fornecidos pelo Dieese, podemos perceber claramente que em suma as empresas terceirizadas não são organizações sólidas. Essas organizações quando apresentam dificuldades financeiras encerram suas atividades, acumulam dívidas trabalhistas e na maioria dos casos ainda não pagam seus funcionários. 
O governo por outro lado, na tentativa de avançar a lógica neoliberal nos espaços públicos tem adotado a estratégia de enfraquecimento da representação sindical. Em contrapartida, os servidores públicos sobretudo organizados em movimentos sindicais, embora persistam na política de resistência, ultimamente eles têm enfrentado muitas dificuldades na luta contra a retirada de seus direitos. As políticas de privatizações e a ofensiva do discurso governamental na mídia, noticiando diariamente que os servidores públicos são os únicos com direitos privilegiados em relação aos demais trabalhadores, isso tem influenciado diretamente no enfraquecimento sindical.

No entender de Druck et al. (2018), as Universidades Públicas, instituições que produzem conhecimento e reúnem os principais intelectuais, criou-se uma situação em que essas instituições se tornaram cúmplices de um amplo processo de precarização do trabalho. À medida que contribuem para a criação de trabalhadores de "segunda categoria", conforme relata a autora. Os terceirizados embora sejam indispensáveis para a funcionalidade da instituição de ensino superior, principalmente na execução de seus serviços básicos. Diante da atual realidade nas universidades, pode-se afirmar que a classe dos terceirizados, mesmo que seja composta por trabalhadores competentes em suas funções, não pertencem legalmente à comunidade universitária.

\section{A percepção das classes representativas da UFR sobre o processo de terceirização no período de 2015 a 2018}

A criação da Universidade Federal de Mato Grosso conforme relata Alves (2006), teve início no século XVIII com sua sede na antiga capital da capitania na Vila Bela da Santíssima Trindade. Houve outras tentativas de criação da instituição no século XIX, mas, não obtiveram êxito os cursos propostos. Somente em 1952 pela Lei n. ${ }^{\circ} 485$ de 5 de setembro que foi criada a Faculdade de Direito de Cuiabá e pela força do Decreto n. ${ }^{\circ} 43.339$ de 3 de dezembro de 1959 que foi reconhecida a primeira Faculdade Matogrossense.

Segundo Alves (2006), o Centro Pedagógico de Rondonópolis em 1982 foi transferido para a sua sede atual localizada na rodovia Rondonópolis-Guiratinga. Em 1985, foram criados os cursos de Licenciatura Plena em História e Geografia, em seguida os cursos de Ciências Exatas, Ciências Contábeis, Letras e Pedagogia totalizando seis cursos de ensino superior. Os avanços no Campus Universitário de Rondonópolis podem ser constatados a partir de 1995, quando teve seu espaço físico ampliado com a construção do prédio da biblioteca, guarita e da Casa do Estudante. Em 2005, o Campus Universitário de Rondonópolis oferecia onze cursos 
de graduação sendo eles o de Biblioteconomia, Ciências Biológicas, Ciências Contábeis, Geografia, História, Informática, letras, Matemática, Pedagogia, Psicologia e Zootecnia.

No ano de 2006, o Campus Universitário de Rondonópolis apresentou um desenvolvimento significativo na ampliação dos cursos ofertados, a criação de trinta vagas para docentes, quinze vagas para servidores técnico-administrativos, e a sete turmas especiais na cidade de Campo Verde e Primavera do Leste sob a tutela do Campus (ALVES, 2006). A partir desse momento histórico, o Campus passava a oferecer quatorze cursos, com a criação dos cursos de Engenharia Agrícola e Ambiental, Engenharia Mecânica e Enfermagem. O projeto de ampliação dos cursos prosseguiu sendo criados novos cursos posteriormente e novas vagas para os ingressos nesta Universidade.

No dia 20 de março de 2018 tem início o marco histórico no Campus Universitário de Rondonópolis, quando o Campus é desmembrado da Universidade Federal de Mato Grosso pela Lei n. ${ }^{\circ} 13.637$ que cria a Universidade Federal de Rondonópolis. Conforme BRASIL (2018) A UFR terá por objetivo ministrar ensino superior, desenvolver pesquisa nas diversas áreas do conhecimento e promover a extensão universitária, caracterizando sua inserção regional.

O Relatório Anual Estatístico (2018) informa a presença de 3716 alunos matriculados no ensino da graduação e 145 alunos matriculados nos cursos de pós-graduação na Universidade Federal de Rondonópolis, com base nas informações do ano de 2017. No relatório são detalhadas as informações referentes os dezenove cursos de graduação e dos quatro cursos de pós-graduação. Em relação ao corpo docente e técnico desta instituição, segundo o relatório estatístico há 297 professores efetivos, 55 professores substitutos e 90 técnico-administrativos, esses servidores estão distribuídos nos três institutos do ICHSInstituto de Ciências Humanas e Sociais, ICEN- Instituto de Ciências Exatas e Naturais, ICAT- Instituto das Ciências Agrárias e Tecnológicas.

Ao analisarmos as respostas dos representantes de cada Classe Representativa quanto à expansão da terceirização nas Universidades Públicas, constataram-se afirmativas direcionadas às políticas de corte de investimento em serviços públicos. As quais, ao fazermos um breve histórico da terceirização nas leis vigentes dentro Administração pública temos o Decreto 200/1967 sobre a descentralização das atividades do Estado e execução indireta de serviços para o setor privado, e em seguida a Lei 6.019 de 1974 que dispõe das regras de contrato temporário nas empresas urbanas.

A pesquisa revelou que os entrevistados percebem o processo de terceirização nas Universidades Públicas pela precarização dos serviços públicos. Os pesquisados citaram 
como exemplos, a redução de concursos públicos para os cargos de técnico-administrativos e docentes e o aumento de contratação de professores substitutos neste processo de terceirização das universidades. Acreditam que tais ações governamentais interferem na qualidade de ensino da universidade e contribuem para a expansão do processo da terceirização nas Universidades Públicas. Tal afirmação de um dos representantes das Classes Representativas:

[...] então principalmente os estudantes né, com a terceirização aí então aumenta como eu estava te falando, a questão dos professores que pode comprometer a qualidade, o desempenho dos estudantes, além das funções no caso dos técnicosadministrativos que somente técnicos-administrativos, eles podem exercer, por exemplo, o acesso a sistemas, acesso a alguns processos [...] (CLASSE A, 2019)

Podemos observar uma similaridade das afirmativas dos pesquisados aos resultados das políticas públicas de redução de investimento e cortes de verbas nas universidades pelo governo. O Estado, por sua vez utiliza dos mecanismos de decretos e leis para incentivar cada vez mais a participação da iniciativa privada na execução dos serviços públicos. A Lei de Responsabilidade Fiscal, por exemplo limita os gastos públicos do governo sob o princípio de economicidade na Administração Pública, em alguns casos pode inclusive proibir a abertura de concursos públicos no país. É por essa ótica que o governo opta em contratar empresas para executarem os serviços públicos ao invés de empossar mais servidores públicos via concurso público no exercício das atividades públicas.

Entretanto, a pesquisa revelou que há controvérsias no princípio de economicidade pelo governo, quando o entrevistado exemplifica o custo de um contrato de terceirização para a tomadora de serviços, quando diz:

[...] um servidor terceirizado para universidade ele é mais caro que o servidor efetivo [...] a oneração da Universidade sai dupla, por exemplo, se um servidor que trabalha na área de limpeza ele tem digamos R $\$ 2000$ de remuneração, a empresa terceirizada ela cobra o dobro ou mais, então, já nisso, a universidade perde nessa política de economia. (CLASSE B, 2019)

Em relação às mudanças da Lei 13.429/17 e as implicações para a categoria, em suma os entrevistados foram unânimes ao afirmarem que poderá haver um comprometimento na qualidade do ensino da educação superior. A terceirização, no ponto de vista dos entrevistados implicará principalmente na carreira docente, caso haja a substituição dos professores concursados por professores contratados. Tal afirmativa, foi evidenciada na fala do entrevistado: 
A aprovação da lei o que a gente vê o seguinte é as implicações diretas em relação à carreira docente. Porque ela vai implicar na extinção dos cargos de professores concursados e eles sendo substituídos por professores contratados, ou seja, todo o processo de precarização e de retirada de direitos junto com essa terceirização vem também a perda da estabilidade da categoria docente. (CLASSE C, 2019)

A nova Lei da Terceirização permite a atividade principal de uma empresa ser terceirizada, ou seja, até mesmo aquelas atividades que envolvam decisões estratégicas de uma organização. Na Administração Pública, as atividades-fim por enquanto não podem ser terceirizadas. Entretanto, podemos observar nos últimos anos o avanço da terceirização sobretudo nas Universidades Públicas, a partir da implantação de políticas públicas de redução de investimentos públicos.

A mais recente foi a publicação do Decreto 9507/18, que ampliou as atividades-meio incluindo mais cargos passíveis da terceirização. Cargos, estes que agora são considerados extintos pela Administração Pública, como os de auxiliar de laboratório, secretário executivo, por exemplo. Outra política governamental foi a publicação da Portaria 443/18 que em suma proíbe a terceirização somente nas atividades que envolvam decisões estratégicas do órgão, sendo assim pode-se perceber que há lacunas na Administração Pública para o avanço do processo de terceirização nas Universidades Públicas Brasileiras.

\footnotetext{
A sutil implementação de ações neoliberais nas universidades públicas pode ser percebida de várias formas, tais como: tratar a Educação como mercadoria e não como um direito, terceirização dos serviços (contratos de trabalho realizados através das fundações privadas e de empresas terceirizadas), flexibilidade das relações de trabalho (tanto para a categoria de funcionários, como para a categoria dos docentes), corte de verbas, parcerias público-privadas, etc. (GRANZOTTO, 2011, p.172)
}

A pesquisa constatou uma grande preocupação por parte dos entrevistados à medida que estão avançando as contratações de profissionais para a docência e para o exercício da função de técnico-administrativo na Universidade Federal de Rondonópolis. O Relatório Anual Estatístico (2018) com base no ano de 2017, revela que há 55 professores substitutos na instituição e no mesmo ano foram contratados 26 professores para compor o corpo docente. Em contrapartida, com base nas informações do mesmo relatório, o edital n. 05/2017 de abertura para concurso público da UFMT - Universidade Federal de Mato Grosso disponibilizou apenas 10 vagas para docentes.

Desse modo, podemos inferir que há insuficiência de professores efetivos na instituição estudada. Estes, por sua vez se encontram licenciados em tratamentos médicos ou em processo de capacitação na carreira docente. A aposentadoria e a transferência do docente 
para outra instituição também são responsáveis por essa deficiência de professores no quadro docente, que na maioria das vezes são supridas pelos editais de seleção para a contratação de professor substituto pelas universidades. Em consonância a esse processo de contratação de servidores pelas universidades, estão os técnico-administrativos que também estão sendo substituídos por profissionais contratados via terceirização.

O processo de substituição de servidores efetivos por terceirizados, esteve presente na fala do entrevistado ao relatar a prestação de serviços dos terceirizados nas secretarias de cursos da UFR: “[..] começam cortando os terceirizados, tinha cinco pessoas que trabalhava nas secretarias dos cursos, agora nós não temos os cinco para dispor, então a gente vai fazer o seguinte, tem três e estes vão fazer o rodízio entre os cinco cursos [...] (CLASSE C, 2019).

Conforme o Relatório Anual Estatístico (2018), a instituição estudada possui um total de 90 técnico-administrativos. Os servidores públicos foram distribuídos da seguinte forma: 11 técnico-administrativos no ICAT- Instituto de Ciências Agrárias e Tecnológicas, 31 no ICEN - Instituto de Ciências Exatas e Naturais, 9 no ICHS -Instituto de Ciências Humanas e Sociais. Os demais 39 técnico-administrativos estão distribuídos nos setores administrativos da universidade. Ainda com base nesse relatório, no de 2017, o edital de concurso público de n. ${ }^{\circ}$ 4/2017 para técnico-administrativo foram contempladas apenas 3 vagas, sendo uma para engenheiro civil, um publicitário, um auxiliar em administração. Deste modo, observa-se que a Universidade Federal de Rondonópolis possui um número insuficiente de técnicoadministrativos atuantes em seus setores e as vagas para os cargos de auxiliar e assistente de administração foram reduzidas em concursos públicos favorecendo assim a contratação de funcionários terceirizados no lugar desses cargos.

Os entrevistados demonstraram em seus depoimentos as consequências dessas políticas públicas de redução de investimentos e de cortes de verbas para os serviços públicos. Tais medidas, no entendimento dos entrevistados resultaram na perda de alguns direitos dos servidores públicos, na extinção de cargos na Administração Pública e na redução de vagas em concursos públicos para o cargo de docente. Além disso, percebem a tentativa do governo de enfraquecer as entidades sindicais, ao contratar trabalhadores terceirizados regidos pela CLT- Consolidação das Leis Trabalhistas no lugar de servidores públicos efetivos.

A intencionalidade do governo de desestabilização dos sindicatos, pode ser vista também na aprovação da Medida Provisória n. ${ }^{\circ} 873 / 19$ pelo presidente Jair Messias Bolsonaro. A Medida Provisória n. ${ }^{\circ}$ 873/19 retira a obrigatoriedade da contribuição sindical descontada do salário do trabalhador a qual passa a ser opcional, e com a devida autorização prévia do trabalhador. Vale salientar, os sindicatos representam os trabalhadores e lutam 
contra a retirada de seus direitos. Nesse sentido, a pesquisa com os entrevistados revela que o processo de terceirização implica na perda de direitos trabalhistas pelo trabalhador.

A gente já vem percebendo isso há muito tempo com o processo de terceirização, ele perde os direitos trabalhistas, ele não tem garantias de trabalho porque a terceirização não significou garantia de trabalho né, até porque existe uma grande rotatividade das empresas terceirizadas no setor público. (CLASSE C, 2019)

Quando perguntado em relação às implicações sociais da terceirização, os entrevistados em suma relacionaram as implicações sociais à exploração de mão de obra do terceirizado, à rotatividade das empresas terceirizadas no setor público e a incerteza da garantia dos direitos trabalhistas para os terceirizados. A precarização do trabalho na universidade estudada, constatou-se sobretudo nas atividades exercidas pelos os trabalhadores terceirizados. Podemos encontrar tais fatos na afirmativa do entrevistado:

[...] a gente tá sofrendo muitos cortes de verbas, então o dinheiro para as instituições diminuiu. É como eu havia dito anteriormente né, que usa o terceirizado, a exemplo do eletricista e da limpeza que foi reduzido em $5 \%$ e eles têm que manter a mesma estrutura, então a gente sobrecarrega esse trabalhador [...] (CLASSE A, 2019).

Conforme os estudos realizados pelo Dieese (2017), a elevada taxa de rotatividade da mão de obra é um dos indicadores mais preocupantes do mercado de trabalho. Pois, representa a incerteza para os trabalhadores de encontrar um novo emprego. $\mathrm{O}$ estudo aponta ainda, que essa rotatividade implica inclusive em salários mais baixos para os trabalhadores, já para o Estado, a rotatividade resulta no aumento de despesas com o seguro-desemprego. Tomando por base esse estudo do Dieese, pode-se afirmar que a terceirização é responsável pela elevada taxa de rotatividade da mão de obra no país, a partir do momento que não oferece garantia de trabalho aos funcionários terceirizados, que estão sujeitos a demissão a todo momento. Contribuindo para o aumento do desemprego no país, a terceirização traz consigo mais problemas sociais que o Estado, por sua vez terá de "pagar a conta".

Em relação à demissão por insuficiência de desempenho pelo PL116/2017, os entrevistados percebem o avanço desse projeto de lei no atual governo, embora já existam mecanismos de demissão do servidor previstos no Plano de Carreira dos servidores públicos. Percebem ainda que há a intenção de perseguição política e de tentativa da desestabilização do servidor público. Afirmam que há um mito em relação a ineficiência de desempenho do servidor público, à medida que a existe o PIA- Plano de Atividade Individual para os docentes, além do PAD - Processo Administrativo Disciplinar e o RJU -Regime Jurídico 
Único que norteiam a carreira do servidor público. Tais afirmativas são encontradas nas afirmativas dos entrevistados:

[...] uma ilusão foi criada, o mito em relação ao professor que o funcionário público é ineficiente. Por exemplo, o professor ele tem que cumprir as horas dele em sala de aula, e mais montar, preparar suas aulas na universidade. Ainda existe o PIA né. Então esse é o administrativo e exige que o professor cumpra, tenha o seu PIA, as atividades administrativas, projeto de pesquisa e projeto de extensão. (CLASSE A, 2019)

Os entrevistados acreditam que caso seja aprovado o PL 116/17, na prática ele não servirá apenas como um instrumento de medida de desempenho do servidor público. Os pesquisados salientam que já existem critérios presente no Plano de Carreira do Servidor Público para a demissão, e mais afirmam que tal projeto poderá implicar em casos de perseguição política no setor público e na desqualificação do servidor público.

Quanto a Vedação de concursos pelo Decreto 9.262/18, os entrevistados acreditam que haverá comprometimento na qualidade do ensino das Universidades Públicas, principalmente nas atividades de pesquisa, na captação de recursos para a produção científica. A ausência de concursos públicos para as universidades atinge a comunidade acadêmica num todo. Em relação aos docentes, contribuirá para o aumento de professores substitutos e a perda de incentivo à pesquisa nas universidades. Podemos constatar tal situação na fala do entrevistado "quando não se abre concurso público você vai contratar o professor substituto com carga horária excedente, esse professor substituto ele não faz pesquisa, ele não faz extensão, ele fica apenas um ensino de graduação" (CLASSEC, 2019).

Silva, Menezes e Vasconcelos (2018) discutem o processo de terceirização na UFR salientando a redução no quantitativo de vagas que iriam compor o quadro de servidores técnico-administrativos mediante a publicação do Decreto 9.262/2018 e da Lei 13.637/18 que cria a Universidade Federal de Rondonópolis. A vedação de concurso para cargos aos quais foram considerados extintos ou apenas acessórios para a Administração Pública possibilitou o avanço significativo da terceirização nas Universidades Públicas, ao passo que as atividades passíveis de serem terceirizadas estão sendo renovadas constantemente deixando uma lacuna para a carreira de servidor público.

Quanto à percepção dos trabalhadores terceirizados, na visão dos entrevistados podese verificar que os entrevistados enxergam os terceirizados como pessoas competentes no exercício de suas funções, mas que sofrem com a precarização do trabalho em que são submetidos. E mais, os pesquisados veem esses trabalhadores com baixo nível de instrução, 
geralmente composto por trabalhadores negros e residentes nas regiões periféricas da cidade que se submetem aos esses empregos, devido ao desemprego estrutural enfrentado pelo país. Tais percepções foram identificadas nas seguintes afirmativas dos entrevistados:

[...] o que a gente questiona é justamente a precarização da condição desse trabalhador nessas universidades, baixos salários, não tem garantia nenhuma de direitos e fica à mercê da conjuntura e do que acontece no mercado. Porque se corta investimento, corta recurso para educação, o primeiro a ser cortado vai ser lá no setor dos terceirizados, ou seja, hoje ele está empregado, amanhã ele não sabe[...] (CLASSE C, 2019)

$\mathrm{Na}$ ausência de vagas para concurso aumenta a contratação de trabalhadores terceirizados no setor público. Na maioria das vezes, esses trabalhadores terceirizados ficam sem receber os direitos trabalhistas devido a constante rotatividade de empresas terceirizadas, e ainda são explorados quando há uma demanda superior de serviços em relação ao número de funcionários terceirizados. A pesquisa revelou que na instituição estudada, a exploração da mão de obra terceirizada no setor de limpeza coma a redução no número de funcionários sem alterar a demanda por serviços limpeza na instituição. O entrevistado da Classe A (2019) relata tal condição no trabalho dos funcionários do setor da limpeza da Universidade Federal de Rondonópolis "[...]a gente vê esse processo durante a limpeza que ainda precariza o trabalho né, porque a gente vê que teve uma diminuição dos recursos [...]”. Tal constatação também se verificou na fala do fiscal de contrato, quando ele diz:

Os terceirizados o setor da Universidade que possui maior número de trabalhadores terceirizados da limpeza ela empresa chamada Congene, ela tem torno de 38 funcionários [..]devido aos cortes do governo federal foi reduzido. (FISCAL DE CONTRATO, 2019)

Quanto às oportunidades da terceirização, os entrevistados conseguem distinguir as oportunidades para a tomadora de serviços e a para a contratante. Um dos entrevistados declarou que não enxerga oportunidades no processo de terceirização: "eu não vejo assim essas oportunidades né não vejo isso como uma grande saída mais para os economistas aí alinhado ao pensamento neoliberal ensinam a grande saída é o setor de serviços né" (CLASSE C, 2019). Já o outro entrevistado, consegue identificar as oportunidades para a tomadora de serviços, neste caso a Universidade Federal de Rondonópolis:

As empresas terceirizadas elas são obrigadas a cumprir com aquilo que está no contrato, ou seja, o serviço da empresa terceirizada com a universidade, ela tem que sair ao contento da contratante da universidade e dentro disso a universidade fiscaliza o trabalho. Tem os fiscais da universidade para que o serviço saia sempre dentro daquilo que a universidade exige. (CLASSE B, 2019) 
$\mathrm{Na}$ afirmativa do outro pesquisado pode notar as oportunidades para a contratante em detrimento da tomadora de serviços:

A universidade é responsável em fazer o pagamento dos direitos trabalhistas para reproduzir décimo terceiro, mas quem faz é a empresa, a universidade só repassa o dinheiro. Ela pode ser processada caso passe o dinheiro para a empresa e a mesma não repasse, aí sim pode dar pode causar implicações para a universidade. (CLASSE A, 2019)

Em relação as dificuldades das universidades com o aumento das empresas terceirizadas, a pesquisa revelou que a maioria dos entrevistados, acreditam que as universidades correm o risco de perderem a sua qualidade na produção de conhecimento, caso haja o avanço da terceirização nas atividades-fim. Tal fato, pode ser verificado na afirmação do entrevistado: “[...] vai descaracterizar todo o papel e a função da universidade pública brasileira ela vai perder toda a sua característica [...]. (CLASSE C, 2019). Outras dificuldades foram mencionadas pelo o outro entrevistado:

Dificuldade e não sei, quanto ao corpo técnico nós vamos ter. Porque quando chegar nos docentes nos professores e tiver empresa particular contratada trazendo professores para fazer o serviço e dar aula não vai ser nunca vai ser na mesma qualidade em que um professor foi escolhido em banca para disciplina tal. (CLASSE B, 2019)

Nesse sentido, a preocupação dos entrevistados se remete as mais recentes publicações do Decreto 9507/18 e a Portaria 443/18, que descrevem que só atividades de decisão de estratégica do órgão que não estão passíveis de terceirização no órgão público, e ainda nesse decreto são citados mais cargos e atividades que já podem ser terceirizadas. No documento são citados principalmente cargos de técnico de educação, como os de assistente de administração, secretário executivo, auxiliar de laboratório. Já nas atividades passíveis de terceirização na Administração Pública são mencionadas as atividades auxiliares de biblioteconomia e documentação, informática, jornalismo, publicidade dentre outras.

A pesquisa revelou ainda que os entrevistados percebem que haverá um comprometimento da qualidade do ensino superior, na medida que aumentará as contratações de profissionais com baixa qualificação para a docência e nas atividades de pesquisa, Atualmente a instituição segundo o Relatório Anual Estatístico (2018), a universidade conta com 82 professores pesquisadores com alunos participantes nas atividades de pesquisa, sobretudo inscritos nos Programa Institucional de Bolsa de Iniciação à Docência (PIBID) e o - Programa Institucional de Bolsa à Iniciação Científica (PIBIC). Nesse sentido, podemos 
perceber a relevância dos professores efetivos na produção de conhecimento, embora o número ainda seja inferior se comparado a outras universidades. Contratar professores substitutos para simplesmente dar aulas na instituição, sem realizar pesquisa comprometerá a qualidade de ensino das Universidades Públicas.

Quando perguntado às iniciativas para a garantida de direitos de classe, os entrevistados responderam que realizam mobilizações, passeatas, debates, acionam o sistema judiciário e fazem parceria com outras entidades sindicais a fim de lutar contra a retirada de direitos. Tais informações estão presentes nas falas dos entrevistados:

Nossa solidariedade, nosso o nosso apoio aos servidores públicos né, porque aí entender que o desmonte da classe dos servidores públicos da universidade né, dos professores e técnicos é o desmonte da universidade que vai chegar, também que vai que vai prejudicar os estudantes. Então a gente sempre tenta andar de mãos dadas com os sindicatos no sentido das bandeiras de luta nas manifestações, nas mobilizações, na garantia dos direitos deles (CLASSE A, 2019)

Constatou-se durante a entrevista realizada com cada um dos representantes das Classes Representativas, que em geral os pesquisados percebem o avanço da terceirização nas universidades e lutam contra a retirada de direito de suas classes. E mais, os pesquisados, associam a nocividade do processo de terceirização ao comprometimento da qualidade de ensino no ensino superior e à descaracterização do servidor público. A mais recente publicação do Decreto 9725/19 sobre a extinção das funções gratificadas dos cargos em comissão no Poder Executivo Federal acentuará o processo da precarização do trabalho nas Universidades Públicas. É notório o acúmulo de atividades acadêmicas pelos docentes e de acordo com a determinação do decreto, as funções exercidas na direção, gestão e coordenação de cursos ficaram isentas de gratificações públicas, tal medida sinaliza para uma governança mais corporativista nas universidades.

\section{Fiscal de contratos e suas atribuições na fiscalização das empresas fornecedores de mão de obras da UFR}

Ao analisarmos os dados obtidos no processo de terceirização do período de 2015 a 2018 na Universidade Federal de Rondonópolis, com base nas informações fornecidas pelo Setor de Supervisão de Compras e Patrimônio (2019) até o período da realização da pesquisa, a instituição possui atualmente 13 fiscais de contratos responsáveis pela fiscalização de todos contratos terceirizados. Os fiscais de contratos podem ser titulares ou auxiliares, os quais são responsáveis de fiscalizar e acompanhar as atividades realizadas pelas empresas terceirizadas 
na instituição. Vale salientar que as atribuições do fiscal de contrato requerem muita responsabilidade e conhecimento da legislação que versa sobre a Administração Pública. Durante a entrevista, o fiscal de contrato relata a sua função de fiscalizar e acompanhar os contratos das empresas terceirizadas, além disso, o pesquisado cita as normativas e editais que um fiscal de contrato necessita tomar conhecimento:

A função do fiscal de contrato é de fazer a fiscalização e acompanhamento do
contrato do qual ele é designado acompanhar ele no âmbito da UFMT. Os fiscais
eles são nomeados pela Proad né, por meio de Portaria Administrativa e eles tem
que tomar conhecimento do contrato que eles estão fiscalizando. Lê todo o edital e
as ordens de serviço da UFMT e a instrução normativa do Ministério do
planejamento. (FISCAL DO CONTRATO, 2019)

No processo de fiscalização das obrigações previstas no contrato de terceirização de fornecimento de mão de obra, o entrevistado menciona as atividades realizadas para o cumprimento desta função:

[...] evitar desvio de função, fazer os processos de pagamento, verificar mensalmente sempre se está pagando FGTS, pagando o INSS, pagando as cestas, se está cumprindo a CCT Convenção Coletiva do trabalho, se está cumprindo todos os deveres da CLT consolidação das Leis Trabalhistas Além disso o trabalho do fiscal ele é bem mais amplo né, ele tem que acompanhar diariamente. Verificar se as pessoas estão vindo, se está tendo o cumprimento da carga horária [...] (FISCAL DO CONTRATO, 2019).

Quando perguntando em relação à prestação de serviços da empresa terceirizada, o pesquisado afirma que o fiscal de contrato verifica a situação de desvio de função de um trabalhador terceirizado, fiscaliza o uso de equipamentos previstos no contrato e o cumprimento das obrigações trabalhistas. Caso haja alguma irregularidade, o entrevistado menciona ainda que a justiça convoca o fiscal de contrato para testemunho em processos trabalhistas da empresa terceirizada que prestou serviços a Universidade.

[...] se os equipamentos estão instalados que são exigidos no contrato, se não tiver tudo instalado fazer os devidos descontos na nota. O trabalho do fiscal, também se estende depois do contrato, por exemplo se uma empresa, uma pessoa entra com uma ação trabalhista ou fiscal ele é chamado para dar os subsídios da Justiça do que aconteceu durante a época da vigência do contrato [...] (FISCAL DO CONTRATO, 2019).

Em caso de irregularidades no cumprimento do contrato, o pesquisado respondeu que o fiscal de contrato notifica a empresa estabelecendo prazo para a correção da irregularidade, se a irregularidade persistir é realizado um processo administrativo e enviado a GECON Gerência de Contratos para a aplicação de sanções previstas na norma do edital de licitação. 
Primeiramente o fiscal notifica a empresa apontando qual é a regularidade, dá um prazo para empresa resolver a situação. Caso ela não resolva aí o fiscal monta um processo administrativo que é encaminhado para gerência de contratos que daí eles vão verificar no edital qual é a penalidade que se aplica, qual que é a sanção que a empresa tem que tomar né ou reforçar ainda para ela, qual que é a para fazer a empresa cumprir a obrigação. Aí caso ela não cumpra aí sim ela é penalizada com base nas normas do edital que ela concorreu para poder prestar o serviço para UFMT. (FISCAL DE CONTRATO, 2019)

Em relação aos critérios para o acompanhamento dos contratos, o entrevistado respondeu que a contratante deve cumprir todo o edital da CCT e a CLT para fiscalizar tais ações, A Universidade Federal de Rondonópolis, ainda não tem o setor de Gestão de Contrato. O serviço de fiscalização dos contratos das empresas terceirizadas na universidade é realizada apenas pelos os fiscais de contrato que encaminham todas as informações para a supervisão da GECON da UFMT de Cuiabá-MT.

Então empresa terceirizada ela tem que cumprir tudo que está em edital as obrigações que estão no edital as obrigações que estão na CLT e as obrigações que estão na CCT e a UFMT fazer esse acompanhamento né por meio dos fiscais de contrato e também por meio da GECON .Porque tudo que o fiscal não conseguir resolver ou é algo muito complexo ele tem que montar um processo administrativo encaminhar para a gerência de contratos para ela tomar as providências caso ocorra irregularidades no cumprimento do contrato por parte da empresa terceirizada. (FISCAL DE CONTRATO, 2019).

Quanto os setores da Universidade Federal de Rondonópolis com mais terceirizados, o pesquisado cita que o setor de limpeza possui o maior número de terceirizados, atualmente está com apenas 38 funcionários. A pesquisa revela ainda, que houve a redução de 46 para 38 funcionários terceirizados, devido à redução de repasse de verbas do Governo Federal. Ainda sobre os terceirizados, o entrevistado comenta sobre sua percepção: "São pessoas que têm um baixo nível de instrução, a maioria das meninas elas têm ensino fundamental né. Aí você percebe que pelo fato de elas possuírem um pouco grau de instrução, a terceirização nesse caso acaba favorecendo a ocorrência de mais acidentes no trabalho" (FISCAL DE CONTRATO, 2019).

Em relação aos riscos da terceirização, o entrevistado afirma que a terceirização pode representar riscos para as universidades públicas caso atinja as atividades-fim. O conceito de atividades-fim na visão de Senhoras (2013, p.156): “A atividade-fim é aquela que demonstra qual a finalidade principal do negócio organizacional, podendo ser melhor compreendida quando lidos o contrato social, legislação ou regimento interno da organização, onde é possível visualizar o registro do objetivo". O fiscal de contrato, reconhece os riscos que 
poderão existir caso haja o avanço da terceirização para as atividades-fim nas Universidades Públicas. A falta de investimento de dinheiro público nas instituições e o incentivo do governo para a participação da iniciativa no setor público, tais fatos podem ser vistos na sucessão de leis aprovadas para regulamentar a terceirização no país, sendo assim é possível que a terceirização irrestrita alcance a esfera pública.

Em relação as oportunidades no processo de terceirização, o entrevistado percebe a oportunidade tanto para tomadora de serviço e como para contratante, sobretudo no exercício das atividades-meio, ao relatar:

Porque você imagina a rotina de Universidade Pública Federal em caso de greve, aí não ter serviço de vigilância, não ter serviço de limpeza, não ter o serviço de portaria ou mesmo servidores empregados nas suas funções. Que são funções mais pesadas né com 75 anos que agora aposentadoria compulsória é 75 anos, aí fica um pouco mais complicado. (FISCAL DE CONTRATO, 2019)

Quanto às iniciativas na prevenção de falhas dos fiscais do contrato, a pesquisa revelou que as irregularidades são apuradas pela GECON e os fiscais podem responder a processos administrativos caso comentam falhas de fiscalização. $O$ pesquisado menciona que a universidade oferece treinamentos e cursos de educação continuada a fim de prever falhas dos fiscais de contrato no exercício de suas atividades. Tal afirmação nota-se quando ele diz:

Primeiramente a Gecon tem que verificar por falta de treinamento, foi falta de atenção do fiscal. Porque tudo que nós fiscais fazemos é sujeito a processo administrativo disciplinar, por isso é muito importante o treinamento a educação continuada inclusive se tiver alguma dúvida solicitar treinamento no tempo. (FISCAL DE CONTRATO, 2019).

A pesquisa realizada com o fiscal de contrato acerca do processo de terceirização nas Universidades Públicas, constatou os mecanismos de fiscalização e acompanhamento dos contratos de terceirização previstos na Lei $n^{\circ}$ 8.666/93 e a aplicabilidade da lei, embora a Universidade Federal de Rondonópolis não possua um setor de gestão de contrato. Tal responsabilidade de fiscalizar e informar sobre as atividades realizadas pelas empresas terceirizadas que atuam na instituição, atualmente é de responsabilidade do Setor de Supervisão de Compras. E mais, a percepção do fiscal de contrato sobre o processo de terceirização difere da percepção das Classes Representativas, o pesquisado considera importante a terceirização nas atividades- meio, pois acredita que o servidor público ao atingir a terceira idade não possui condições de exercer às atividades colaborativas, enquanto as 
Classes Representativas, consideram nocivo o processo de expansão da terceirização nas universidades.

\section{Considerações Finais}

A terceirização na Administração Pública surge com uma alternativa de contratação de pessoal para suprir a insuficiência de servidores públicos, sobretudo nas atividades-meio. Embora, favoreça a obtenção de lucro sobre a exploração da força de trabalho, o processo de terceirização em grande escala pode representar uma série de riscos aos direitos do trabalhador. Por outro lado, questiona-se a qualidade dessa prestação dos serviços no setor público, quando os estudos realizados na área apontam para a precarização do trabalho. Muitas empresas surgem aleatoriamente, outras têm pouco tempo de atuação no mercado e na maioria dos casos estas empresas acumulam dívidas trabalhistas.

A pesquisa revelou que as Classes Representativas percebem o processo de terceirização nas Universidades Pública, a partir do momento que os entrevistados notam esse fenômeno principalmente no aumento das contratações dos professores substitutos e a presença de servidores terceirizados nas secretarias dos cursos desta instituição. Outra constatação interessante durante a realização da pesquisa documental, foi a redução de vagas nos editais de concurso público da Universidade Federal de Mato Grosso, instituição tutora da atual Universidade Federal de Rondonópolis.

As Classes Representativas da Universidade Federal de Rondonópolis, sobretudo os professores, alunos e técnico-administrativos temem o avanço do processo de terceirização na atividade principal da instituição. As informações fornecidas pelo Setor de Supervisão de Compras no ano de 2019, revelam a existência de dezesseis empresas terceirizadas atuantes na Universidade Federal de Rondonópolis e um total de cento e oito terceirizados, a partir de tais constatações pode-se presumir que a política de contratação de servidores continuará sendo adotada por esta instituição.

A aprovação da Lei da Terceirização aliada a implantação de políticas públicas sobretudo de cunho neoliberal pelo governo nas universidades, já sinalizam para a expansão da terceirização e a privatização do ensino superior nas Universidades Públicas. A redução de verbas destinadas às universidades, o corte dos concursos públicos e a desestabilização do servidor público fazem parte de um conjunto de estratégias governamentais que visam reduzir ao máximo o funcionalismo público brasileiro. 
Atualmente, existem poucos estudos sobre as implicações do processo de terceirização na Administração Pública, especialmente nas IES - Instituições de Ensino Superior. Presumese que sejam inúmeras as dificuldades de realizar esse tipo de pesquisa nas universidades. $\mathrm{O}$ estudo de caso em questão, apresentou dificuldades de coletar informações mais aprofundadas sobre o processo de terceirização na Universidade Federal de Rondonópolis devido a inexistência do setor de Gestão de Contratos, a instituição está ainda subordinada à GECON Gerência de Contratos da Universidade Federal de Mato Grosso.

Nos últimos anos, são inúmeras as dificuldades enfrentadas pelas universidades: a falta de verbas para a produção científica, a insuficiência de vagas nos concursos públicos, precarização do trabalho docente, e por último a intenção do governo de expansão os serviços públicos para a iniciativa privada, diante de tais constatações espera-se que o estudo realizado na Universidade Federal de Rondonópolis promova novos questionamentos acerca da expansão da terceirização nas universidades públicas do país e incentive estudos mais aprofundados sobre os impactos da terceirização em todos os Campus da Universidade Federal de Mato Grosso.

\section{Referências}

ANDERSON, Perry. Balanço do neoliberalismo. In.: SADER, Emir; GENTILI, Pablo. Pósneoliberalismo: As políticas sociais e o Estado democrático. Rio de Janeiro: Paz e Terra, 1995.

ALVES, Laci Maria de Araújo (Org.). Campus de Rondonópolis - UFMT: três décadas de história - (1976-2006). Cuiabá: EdUFMT, 2006.

ALVES, Giovanni. Trabalho e Sindicalismo no Brasil dos anos 2000: dilemas da era neoliberal. In: ANTUNES, Ricardo. (org.). Riqueza e Miséria do Trabalho no Brasil. São Paulo: Boitempo, 2006.p.173-193.

AQUINO, Cassio Adriano Braz et al. O fenômeno da precarização e da flexibilização laboral no âmbito da universidade pública brasileira: o caso dos professores substitutos. Athenea Digital, Campinas, v. 1, n. 14, p.173-193, mar. 2014.

ANTUNES, Ricardo. A Sociedade da Terceirização Total. ABET, SI, v. 14, n. 1, p.6-12, jun. 2015. Semestral.

BEHRING, Elaine Rossetti. Brasil em Contra-Reforma: desestruturação do Estado e perda de direitos.2. ed. São Paulo: Cortez, 2008.

BRASIL. Decreto-Lei $\mathrm{n}^{\circ}$ 200, de 25 de fevereiro de 1967. Disponível em: http://www.planalto.gov.br/ccivil_03/decreto-lei/del0200.htm. Acesso em: 15 mar. 2019. 
Câmara dos Deputados. Projeto de Lei n4330, 26 de outubro de 2004. Disponível em: $\quad$ http://www.camara.leg.br/proposicoesWeb/fichadetramitacao?idProposicao=267841. Acesso em: 20 mar. 2019.

Lei 9.637, de 15 de maio de 1998. Disponível em: http://www.planalto.gov.br/ccivil_03/LEIS/L9637.htm. Acesso em: 13 fev.2019.

Lei 13.429, de 31 de março de 2017. Disponível em: http://www.planalto.gov.br/ccivil_03/_Ato2015-2018/2017/Lei/L13429.htm. Acesso em: 02 jan. 2019.

Decreto $\mathrm{n}^{\mathrm{o}}$ 9507, de 21 de setembro de 2018. Disponível em: http://www.planalto.gov.br/ccivil_03/_Ato2015-2018/2018/Decreto/D9507.htm. Acesso em: 13 mar. 2019.

Lei no6.019, de 3 janeiro de 1974. Disponível em: http://www.planalto.gov.br/ccivil_03/LEIS/L6019.htm. Acesso em: 4 dez. 2018.

Portaria n443, de 27 de dezembro de 2018. Disponível em: http://www.in.gov.br/materia/-/asset_publisher/Kujrw0TZC2Mb/content/id/57219256.

Acesso em: 12 de fev. 2019

. Lei complementar $\mathrm{n}^{\circ} 101$, de 04 de maio de 2000. Disponível em: http://www.planalto.gov.br/ccivil_03/LEIS/LCP/Lcp101.htm. Acesso em: 03 dez. 2018.

. Senado Federal. Projeto de Lei do Senado No 116. /2017(Complementar). Disponível em: https://www25.senado.leg.br/web/atividade/materias/-/materia/128876. Acesso em: 05 mar. 2019.

Decreto $\mathrm{n}^{\mathrm{o}}$ 2.271, de 07 de julho de 1997. Disponível em: http://www.planalto.gov.br/ccivil_03/decreto/d2271.htm. Acesso em: 15 jul .2018.

Lei $\mathrm{n}^{\mathbf{0}}$ 13.637, de 20 de março de 2018. Disponível em: http://www.planalto.gov.br/ccivil_03/_ato2015-2018/2018/Lei/L13637.htm. Acesso em: 02 nov.2018.

Lei $\mathrm{n}^{\mathrm{o}}$ 8.666, de 21 de junho de 1993. Disponível em: http://www.planalto.gov.br/ccivil_03/Leis/L8666cons.htm.Acesso em: 04 jan. 2019.

Medida Provisória $\mathrm{n}^{\circ} 873$, de 01 de março de 2019. Disponível em: http://www.planalto.gov.br/ccivil_03/_Ato2019-2022/2019/Mpv/mpv873.htm.Acesso em: 03 fev. 2019.

. Decreto $\mathrm{n}^{\circ}$ 9.725, de 12 de março de 2019. Disponível em: http://www.planalto.gov.br/ccivil_03/_ato2019-2022/2019/decreto/D9725.htm. Acesso em: 17 abr. 2019.

CONSEPE. Resolução nº158, de 29 de novembro de 2010.

CRESWELL, John W. Projeto de pesquisa: métodos qualitativo, quantitativo e misto. 3.ed. Porto Alegre: Artmed, 2010. 
DIEESE - DEPARTAMENTO INTERSINDICAL DE ESTATÍSTICA E ESTUDOS SOCIOECONÔMICOS. Terceirização e precarização das condições de trabalho: condições de trabalho e remuneração em atividades tipicamente terceirizadas e contratantes.

DRUCK, Maria da Graça et al. A terceirização no serviço público: particularidades e implicações. In: CAMPOS, André Gambier (org.). Terceirização do Trabalho no Brasil: novas e distintas perspectivas para o debate. Brasília: Ipea, 2018.

- Maria da Graça. Terceirização: (Des) Fordizando a Fábrica - um estudo do complexo petroquímico da Bahia, Campinas, 1995. (Tese de Doutoramento. UNICAMP/IFCH).

GRANZOTTO, Tania Maria. A Implementação de ações neoliberais nas Universidades Públicas. Serviço Social \& Saúde, Campinas, v. 10, n. 12, p.171-196, dez. 2011.

KITAGAWA, A.A.; SILVA, M.A. A terceirização do trabalho num cenário de expansão da Universidade Federal de Mato Grosso. Disponível em:http://eventosacademicos.ufmt.br/index.php/semiedu/semiedu2017/paper/viewFile/1023/1 159. Acesso em: 15 mar. 2019.

MARCELINO, Paula Regina Pereira. Honda: terceirização e precarização -a outra face do toyotismo. In: ANTUNES, Ricardo (org.). Riqueza e Miséria do Trabalho no Brasil. São Paulo: Boitempo, 2006. p.93-113

POCHMANN, Márcio. Desempregados do Brasil. In: ANTUNES, Ricardo (org.). Riqueza e Miséria do Trabalho no Brasil. São Paulo: Boitempo, 2006. p.59-73.

RICHARDSON, Roberto Jarry. Pesquisa social: métodos e técnicas. 4.ed. São Paulo: Atlas, 2017.

ROSSO, Sadi Dal. Mais trabalho: A intensificação do labor na sociedade contemporânea. Sao Paulo: Boitempo, 2008.

RUSSO, G. M.; LEITÃO, S. P. Terceirização: uma análise desconstrutivista. Organizações \& Sociedade, v. 13, n. 36, p. 107-123, 2006.

SANTOS, Ariovaldo de Oliveira. A nova crise do sindicalismo internacional. In: ANTUNES, Ricardo (Org.). Riqueza e Miséria do Trabalho no Brasil. São Paulo: Boitempo, 2006. p.447459.

SENHORAS, Eloi Martins. Controvérsias sobre as relações negociais com o setor público: um estudo sobre a terceirização no Brasil. Scientia Iuris, Londrina, v. 17, n. 2, p.149-166, dez. 2013.

SILVA, Aura Santana Campos; MENEZES, Pamela Jordana de; VASCONCELOS, Kamila Senna. Reflexos da Terceirização na implantação da Universidade Federal - UFR. In: CONGRESSO DE PESQUISA EM EDUCAÇÃO, 9. 2018, Rondonópolis. Anais [...] Rondonópolis: UFMT, 2018. p. 1 - 8. 
UNIVERSIDADE FEDERAL DE MATO GROSSO. Anuário Estatístico 2018 - Ano Base 2017.

http://www1.ufmt.br/anuarioestatistico/arquivos/de1fe92638319ba0be5960867481e363.pdf.

Acesso em: 11 fev.2019. 